ÉGYPTE monde arabe

\section{Égypte/Monde arabe}

$34 \mid 1998$

Droits d'Égypte : histoire et sociologie

\title{
Ron Shaham, Family and the Courts in Modern Egypt
}

\section{Baudouin Dupret}

\section{(2) OpenEdition}

\section{Journals}

Édition électronique

URL : https://journals.openedition.org/ema/1552

DOI : 10.4000/ema.1552

ISSN : 2090-7273

\section{Éditeur}

CEDEJ - Centre d'études et de documentation économiques juridiques et sociales

\section{Édition imprimée}

Date de publication : 31 décembre 1998

Pagination : 285-287

ISSN : 1110-5097

\section{Référence électronique}

Baudouin Dupret, « Ron Shaham, Family and the Courts in Modern Egypt », Égypte/Monde arabe [En ligne], 34 | 1998, mis en ligne le 08 juillet 2008, consulté le 07 juillet 2022. URL : http:// journals.openedition.org/ema/1552 ; DOI : https://doi.org/10.4000/ema.1552

Ce document a été généré automatiquement le 7 juillet 2022.

Tous droits réservés 


\title{
Ron Shaham, Family and the Courts in Modern Egypt
}

\author{
Baudouin Dupret
}

\section{RÉFÉRENCE}

Ron Shaham, Family and the Courts in Modern Egypt. A Study Based on Decisions by the Sharîa Courts,1900-1955, Leiden-New York-Köln, Brill, 1997

1 La recherche extrêmement fouillée entreprise par Ron Shaham nous fournit un matériau incomparable pour l'étude juridique et judiciaire des changements dans les représentations de la famille en Egypte contemporaine et dans le traitement qui leur a été donné devant les cours et tribunaux de la sharî'a (al-mahâkim al-shar'iyya). Ses deux sources majeures sont les revues Majallat al-ahkâm al-shar'iyya (entre 1902 et 1923) et alMuhâmât al-shar'iyya (entre 1929 et 1955). Il ne s'agit pas de recueils exhaustifs de la jurisprudence de ces tribunaux de la sharîa, mais d'un guide à l'usage des professionnels visant à leur fournir des clarifications sur des questions de droit matériel, d'administration de la preuve et de procédure. La structure du livre est simple : trois parties consacrées respectivement au mariage, au divorce et aux relations inter-générationnelles; chaque partie est composée d'un certain nombre de chapitres à chaque fois divisés en deux parties, l'une consacrée à l'arrière-plan juridique de la matière, l'autre à son traitement jurisprudentiel. L'analyse politique, économique, sociologique et anthropologique du matériau demeure par contre étonnamment faible. Il s'agit d'un travail proprement islamologique traitant d'une section récente de l'histoire juridique égyptienne. On ne s'étonnera dès lors pas de sa précision philologique et technique, mais on remarquera par contre sa tendance à tomber dans un certain travers orientaliste qui voit dans le magistrat un cadi de la sharî́a plutôt qu'un juge administrant le droit égyptien.

2 Il est extrêmement difficile de rendre compte du livre de Ron Shaham dans son ensemble. On suggérera plutôt de s'y référer en fonction de questions précises que l'on 
peut être amené à se poser dans les domaines de la dot, du contrat, des fiançailles, de l'âge minimum au mariage, de l'enregistrement de l'acte de mariage, des pensions alimentaires, du devoir d'obéissance, du divorce et de ses conséquences, de la paternité, des pensions alimentaires aux enfants et aux parents, de la garde et de la tutelle, de la transmission de la propriété. Ce n'est qu'en conclusion du livre qu'on peut profiter d'une vue d'ensemble des transformations ayant affecté la famille tout au long de ce demi-siècle.

3 Les stratégies judiciaires - et particulièrement des femmes - constituent l'une des questions majeures auxquelles l'ouvrage apporte des éléments d'information essentiels. On sait que les pratiques juridiques locales étaient souvent plus sévères pour une série de personnes que ne l'étaient les dispositions du figh. Une des stratégies poursuivies en justice pouvait dès lors consister à demander que l'inégalité, entre les sexes par exemple, soit entièrement contenue dans ses limites shar'î. C'est ainsi que de nombreuses requêtes de femmes portent sur le droit à posséder en propre leur douaire, à s'opposer à un mariage contraire à leur volonté, à demander une pension maritale, à obtenir que soit puni le mari violent, voire même à jouer des répudiations suspendues et des promesses de divorce pour obliger le mari à les libérer du mariage contre sa volonté. L'étude de cette stratégie de recours à une sharî'a présentée comme "progressiste» contre la coutume "rétrograde» est d'autant plus intéressante qu'aujourd'hui encore, elle constitue l'axe majeur de l'action de juristes féministes qui cherchent à promouvoir la condition féminine dans le cadre d'une référence islamique qu'elles ne remettent jamais en question.

4 L'ouvrage permet aussi d'observer l'étonnante transformation qui a touché en Egypte l'administration de la justice et particulièrement le métier de juger. Tenus d'appliquer le droit islamique dans sa version hanafite, les juges se référaient à des sources classiques (Radd al-muhtâr d'Ibn 'Âbidîn, al-Durr al-mukhtâr de Haskafî, al-Jâmï al-saghîr d'al-Shaybânî, etc.). Mais ils disposaient également de toute la marge d'interprétation que leur autorisaient ces sources, quand ils étaient confrontés à de nouvelles circonstances. C'est ainsi que certains juges ont pu argumenter que le travail salarié de la femme était nécessaire à la renaissance nationale et à la prospérité familiale, ce qui interdisait donc au mari de s'y opposer. Mais, au-delà de ces attitudes ponctuelles, ce sont les mutations de l'activité même du juge qu'il convient d'observer attentivement. Contrairement à de nombreux analystes qui affirment que le juge a généralement ignoré ou interprété restrictivement les réformes, Ron Shaham tend à montrer que son attitude était au contraire complexe et diverse. Certains juges étaient effectivement réticents à appliquer les réformes et adoptaient donc des mesures escapistes, mais d'autres se contentaient de les mettre en oeuvre d'une manière purement technique, alors qu'une troisième catégorie, enfin, s'identifiait avec les objectifs des réformes et les soutenait en conséquence.

5 En conclusion, on dira à la fois l'immense richesse de l'ouvrage et la déception face au manque de mise en perspective sociologique et anthropologique. Le matériau est fascinant et son traitement est rigoureux, mais son exploitation nous laisse parfois sur notre faim. 


\section{AUTEUR}

BAUDOUIN DUPRET

CNRS/Cedej 